\title{
Effects of Parent Characteristics on the Presence and the Progression of Retinopathy of Prematurity
}

\author{
Sabit Kimyon (10) \\ Department of Ophthalmology, Gaziantep University School of Medicine, Gaziantep, Turkey
}

ORCID IDs of the authors: S.K. 0000-000I-9194-984I

Cite this article as: Kimyon S. Effects of Parent Characteristics on the Presence and the Progression of Retinopathy of Prematurity. Cyprus J Med Sci 2019; 4(2): 12|-4.

BACKGROUND/AIMS

To investigate the effects of maternal and paternal risk factors in the development of retinopathy of prematurity (ROP).

\section{MATERIAL and METHODS}

The medical records of premature infants examined between 2015 and 2018 were included in this retrospective study. Gestational age, birth weight, sex, time spent in the neonatal intensive care unit (NICU), maternal and paternal ages, level of education, employment, and smoking were recorded.

\section{RESULTS}

Data of 438 infants who were screened for ROP were included in the study. The mean gestational age of the infants was $31.9 \pm 2.9$ weeks, mean birth weight was $1727.8 \pm 543.7 \mathrm{~g}$, and mean time spent in the NICU was $36.5 \pm 24.5$ days. Lower gestational age, lower birth weight, and more time spent in the NICU significantly increased the presence of any stage and treatment requiring ROP ( $p<0.00 \mathrm{O})$. Maternal and paternal ages, smoking, education level, and employment did not have any significant relationship with the presence of any stage or treatment requiring $\mathrm{ROP}(\mathrm{p}>0.05)$.

\section{CONCLUSION}

The major risk factors for ROP are gestational age, birth weight, and time spent in the NICU where infants receive supplemental oxygen. There was no any relationship between paternal demographics and presence of any stage and treatment requiring ROP.

Keywords: Retinopathy of prematurity, risk factors, parent characteristics, parental age, parental smoking

\section{INTRODUCTION}

Retinopathy of prematurity (ROP) is one of the leading causes of preventable blindness in children that primarily targets preterm infants $(\mathrm{I}, 2)$. ROP is a multifactorial disease with many risk factors (3). The major risk factors for development of ROP are small gestational age, low birth weight (4), and use of supplemental oxygen (5). Other infantile risk factors include respiratory distress syndrome (6), mechanical ventilation (7), blood transfusion (8), necrotizing enterocolitis (9), sepsis (I0), and the time spent in the neonatal intensive care unit (NICU) (II).

Previous studies investigated the maternal risk factors of ROP. There are conflicting results regarding the effects of preeclampsia $(12,13)$, maternal age $(14,15)$, maternal diabetes $(16,17)$, and smoking $(18,19)$ on the development of ROP.

The infantile risk factors for development of ROP have been well established, but there are less and conflicting data regarding the maternal risk factors and very limited data about the paternal risk factors in the literature. The aim of the present study was to investigate the effects of maternal and paternal risk factors in the development of ROP.

\section{MATERIAL and METHODS}

This was a retrospective study was conducted in Gaziantep University Hospital, Turkey. The study was approved by the ethics committee in accordance with the Declaration of Helsinki. The medical records of premature infants examined between 2015 and 2018 in the Ophthalmology Department of Gaziantep University Hospital were included in the study. 
Gestational age, birth weight, sex, time spent in the NICU, maternal and paternal ages, level of education, employment, and smoking during pregnancy were recorded. The presence of ROP, stage and zone of the disease, treatment for ROP, and any adverse event regarding ROP were also recorded. The classification of ROP and the decision for treatment were performed according to the criteria determined by the early treatment for ROP study group (20). Informed consent was not obtained from the patients and parents due to the retrospective nature of the present study.

\section{Statistical Analysis}

Statistical analysis was performed using Statistical Package for the Social Sciences version 22.0 for Windows (IBM Corp.; Armonk, NY, USA). Chi-square test, independent samples t-test, and Mann-Whitney $U$ test were used to evaluate the results. $A$ $p$ value $<0.05$ was considered statistically significant.

\section{RESULTS}

Data of 438 infants who were screened for ROP were included in the study. The patient and parent demographics are shown in Table I. Data regarding the presence and severity of ROP are shown in Table 2.

Maternal and paternal ages were not significantly associated with the presence of ROP. Maternal and paternal smoking did not affect the presence of ROP. Lower gestational age, lower birth weight, and more time spent in the NICU significantly increased the presence of ROP (Table 3). The collected data were also evaluated between treated and untreated infants for ROP. Gestational age, birth weight, and time spent in the NICU were significantly different between the treated and untreated ROP groups (Table 4).

\section{DISCUSSION}

Retinopathy of prematurity affects preterm infants (I). Most of the infantile risk factors for development of the disease have been discussed by previous studies. However, there are less data regarding the maternal and paternal risk factors of the disease. Moreover, existing data of maternal and paternal risk factors have conflicting results.

The most important risk factors for the disease are small gestational age, low birth weight, and oxygen requirement. Palmer et al. (4) reported that small gestational age and low birth weight are risk factors for development of ROP. York et al. (5) showed that not only supplemental oxygen requirement but also fluctuations in $\mathrm{PaO}_{2}$ are associated with the presence and progression of ROP. In our study, gestational age and birth weight were significantly lower, and time spent in the NICU where infants are treated with supplemental oxygen was significantly higher in infants with ROP. These significant differences persisted among infants with ROP when we divided them into the treated and untreated groups.

There are conflicting results about the effect of maternal risk factors on the development of ROP. Wu et al. (14) reported that older maternal age is a risk factor for development of ROP. On the other hand, Uchida et al. (I5) showed that ROP develops more frequently from younger mothers. Concurrently, Kanungo et al. (2I) reported that maternal age does not affect the devel- opment of stage 3 or higher ROP. Similarly, in our study, maternal age did not have an influence on the presence of any stage ROP or treatment requiring ROP. Maternal smoking increases the risk of low birth weight and preterm delivery (22). Hirabayashi et al. (23) reported that maternal smoking decreases the incidence of ROP. However, Spiegler et al. (18) showed that maternal smoking increases the incidence of ROP. In our study, we could not find an association between maternal smoking and presence of any stage or treatment requiring ROP. Previous studies showed that lower maternal education is associated with preterm birth

\begin{tabular}{|c|c|c|}
\hline & $n(\%)$ & Mean $\pm S D$ \\
\hline Gestational age (weeks) & $438(100)$ & $31.9 \pm 2.9$ \\
\hline Birth weight (g) & $438(100)$ & $1727.8 \pm 543.7$ \\
\hline \multicolumn{3}{|l|}{ Sex } \\
\hline -Male & $227(51.8)$ & \\
\hline -Female & $211(48.2)$ & \\
\hline Time spent in the NICU (days) & $438(100)$ & $36.5 \pm 24.5$ \\
\hline Maternal age (years) & $438(100)$ & $28.0 \pm 6.2$ \\
\hline Paternal age (years) & $438(100)$ & $32.1 \pm 6.9$ \\
\hline Maternal smoking (pack-year) & $438(100)$ & $0.9 \pm 2.8$ \\
\hline Paternal smoking (pack-year) & $438(100)$ & $6.6 \pm 9.3$ \\
\hline \multicolumn{3}{|l|}{ Maternal education } \\
\hline -Primary school & $312(71.2)$ & \\
\hline -High school & $69(15.8)$ & \\
\hline -University & $57(13)$ & \\
\hline \multicolumn{3}{|l|}{ Paternal education } \\
\hline -Primary school & $267(61.0)$ & \\
\hline -High school & IOI (23.0) & \\
\hline -University & $70(16.0)$ & \\
\hline \multicolumn{3}{|l|}{ Maternal employment } \\
\hline -Unemployed & $384(87.7)$ & \\
\hline -Civil servant & $32(7.3)$ & \\
\hline -Own business & $19(4.3)$ & \\
\hline -Worker & $3(0.7)$ & \\
\hline \multicolumn{3}{|l|}{ Paternal employment } \\
\hline -Unemployed & $4(0.9)$ & \\
\hline -Civil servant & $60(13.7)$ & \\
\hline -Own business & $122(27.9)$ & \\
\hline -Worker & $252(57.5)$ & \\
\hline
\end{tabular}

TABLE 2. ROP presence and severity among the screened infants $n(\%)$

$\begin{array}{lc}\text { No ROP } & 201(45.9) \\ \text { Mild ROP } & 134(30.6) \\ \text { Type 2 ROP } & 13(3) \\ \text { Type I ROP } & 90(20.5)\end{array}$

$\mathrm{N}$ : number; ROP: retinopathy of prematurity 


\begin{tabular}{|c|c|c|c|}
\hline & No ROP & Any stage ROP & $p$ \\
\hline Gestational age (weeks) & $33.3 \pm 2.5$ & $30.7 \pm 2.7$ & $<0.001$ \\
\hline Birth weight (g) & $1979.8 \pm 551.8$ & $1508.5 \pm 430.5$ & $<0.001$ \\
\hline Time in the NICU (days) & $27.9 \pm 22.4$ & $43.9 \pm 23.8$ & $<0.001$ \\
\hline Maternal age (years) & $28.6 \pm 6.4$ & $27.6 \pm 6.1$ & 0.108 \\
\hline Paternal age (years) & $32.5 \pm 6.9$ & $31.8 \pm 6.8$ & 0.272 \\
\hline Maternal smoking (pack-year) & $0.8 \pm 2.3$ & $1.1 \pm 3.2$ & 0.320 \\
\hline Paternal smoking (pack-year) & $5.6 \pm 7.8$ & $7.5 \pm 10.4$ & 0.077 \\
\hline \multicolumn{4}{|l|}{ Sex } \\
\hline -Male & 94 & 133 & 0.051 \\
\hline -Female & 107 & 104 & \\
\hline \multicolumn{4}{|l|}{ Maternal education } \\
\hline -Primary school & 137 & 175 & 0.396 \\
\hline -High school & 34 & 35 & \\
\hline -University & 30 & 27 & \\
\hline \multicolumn{4}{|l|}{ Paternal education } \\
\hline -Primary school & 115 & 152 & 0.109 \\
\hline -High school & 46 & 55 & \\
\hline -University & 40 & 30 & \\
\hline \multicolumn{4}{|l|}{ Maternal employment } \\
\hline -Unemployed & 169 & 215 & 0.068 \\
\hline -Civil servant & 17 & 15 & \\
\hline -Own business & 14 & 5 & \\
\hline -Worker & 2 & । & \\
\hline \multicolumn{4}{|l|}{ Paternal employment } \\
\hline -Unemployed & I & 3 & 0.172 \\
\hline -Civil servant & 34 & 26 & \\
\hline -Own business & 59 & 63 & \\
\hline -Worker & 107 & 145 & \\
\hline
\end{tabular}

and poor health of the newborn $(24,25)$. In our study, there was no any difference between maternal education levels and presence of ROP. Maternal employment has been shown to reduce or does not affect the incidence of preterm delivery $(26,27)$. Similarly, we could not find a relationship between maternal employment and presence of ROP.

Existing literature has limited information about the paternal risk factors of ROP. There are conflicting studies about the effect of paternal age on preterm birth. Astolfi et al. (28) reported that the risk of preterm delivery increases with advanced paternal age. Conversely, Alio et al. (29) found that preterm delivery risk decreases with paternal age. One might think that if paternal age affects preterm delivery, it can affect the presence of ROP, but that was not the case in our study. We could not find any relationship between paternal age and presence of ROP. Ko et al. (22) showed that paternal smoking does not have an effect on preterm birth of low birth weight, which are major risk factors for development of ROP. Similarly, we could not find an association between paternal

\begin{tabular}{|c|c|c|c|}
\hline & Treated ROP & Untreated ROP & $\mathbf{p}$ \\
\hline Gestational age (weeks) & $29.9 \pm 2.8$ & $31.1 \pm 2.6$ & 0.001 \\
\hline Birth weight (g) & $|423.0 \pm 4| 1.8$ & $1553.8 \pm 434.6$ & 0.026 \\
\hline Time in the NICU (days) & $50.0 \pm 26.1$ & $40.7 \pm 21.9$ & 0.007 \\
\hline Maternal age (years) & $27.6 \pm 5.7$ & $27.6 \pm 6.3$ & 0.959 \\
\hline Paternal age (years) & $31.4 \pm 6.4$ & $31.9 \pm 7.0$ & 0.621 \\
\hline Maternal smoking (pack-year) & $1.1 \pm 3.2$ & $1.0 \pm 3.3$ & 0.874 \\
\hline Paternal smoking (pack-year) & $8.1 \pm 12.1$ & $7.2 \pm 9.4$ & 0.518 \\
\hline \multicolumn{4}{|l|}{ Sex } \\
\hline -Male & 52 & 81 & 0.183 \\
\hline -Female & 32 & 72 & \\
\hline \multicolumn{4}{|l|}{ Maternal education } \\
\hline -Primary school & 63 & 112 & 0.792 \\
\hline -High school & 13 & 22 & \\
\hline -University & 8 & 19 & \\
\hline \multicolumn{4}{|l|}{ Paternal education } \\
\hline -Primary school & 62 & 90 & 0.070 \\
\hline —High school & 14 & $4 \mid$ & \\
\hline -University & 8 & 22 & \\
\hline \multicolumn{4}{|l|}{ Maternal employment } \\
\hline -Unemployed & 78 & 137 & 0.673 \\
\hline -Civil servant & 5 & 10 & \\
\hline -Own business & 1 & 4 & \\
\hline -Worker & 0 & 1 & \\
\hline \multicolumn{4}{|l|}{ Paternal employment } \\
\hline -Unemployed & 1 & 2 & 0.196 \\
\hline -Civil servant & 5 & 21 & \\
\hline -Own business & 20 & 43 & \\
\hline -Worker & 58 & 87 & \\
\hline
\end{tabular}

smoking and presence of ROP. Shapiro et al. (30) reported that lower paternal education increases the risk for preterm birth. In our study, we did not find a relationship between paternal education and presence of ROP. In addition, there was no any relationship between paternal employment and presence of ROP.

Our study has some limitations. First, the retrospective nature of our study limits the accuracy of our results. Second, our study was conducted in a single center; a multicentric study is required for more detailed results.

In conclusion, the major risk factors for ROP are gestational age, birth weight, and time spent in the NICU where infants receive supplemental oxygen. These risk factors affect the presence of both any stage and treatment requiring ROP. Maternal and paternal ages, smoking, education level, and employment did not have any significant relationship with the presence of any stage or treatment requiring ROP. Further studies are needed because of the conflicting results in the literature. 
Ethics Committee Approval: Ethics committee approval was received for this study from Gaziantep University Clinical Research and Ethics Committee (Approval Date: 19.06.2017, Approval Number: 247).

Informed Consent: Informed consent was not obtained from the patients and parents due to the retrospective nature of the study.

Peer-review: Externally peer-reviewed.

Conflict of Interest: The author has no conflicts of interest to declare.

Financial Disclosure: The author declared that this study has received no financial support.

\section{REFERENCES}

I. Good WV, Hardy RJ, Dobson V, Palmer EA, Phelps DL, Quintos M, et al. Early Treatment for Retinopathy of Prematurity Cooperative Group. The incidence and course of retinopathy of prematurity: findings from the early treatment for retinopathy of prematurity study. Pediatrics 2005; 116: 15-23. [CrossRef]

2. Gilbert C, Fielder A, Gordillo L, Quinn G, Semiglia R, Visintin P, et al. Characteristics of infants with severe retinopathy of prematurity in countries with low, moderate, and high levels of development: implications for screening programs. Pediatrics 2005; II5: 518-25. [CrossRef]

3. Smith LE. Pathogenesis of retinopathy of prematurity. Semin Neonatol 2003; 8: 469-73. [CrossRef]

4. Palmer EA, Flynn JT, Hardy RJ, Phelps DL, Phillips CL, Schaffer DB, et al. Incidence and early course of retinopathy of prematurity. The Cryotheraphy for Retinopathy of Prematurity Cooperative Group. Ophthalmology 1991; 98: 1628-40. [CrossRef]

5. York JR, Landers S, Kirby RS, Arbogast PG, Penn JS. Arterial oxygen fluctuation and retinopathy of prematurity in very-low-birthweight infants. J Perinatol 2004; 24: 82-7. [CrossRef]

6. Yang CS, Chen SJ, Lee FL, Hsu WM, Liu JH. Retinopathy of prematurity: screening, incidence and risk factors analysis. Zhonghua Yi Xue Za Zhi (Taipei) 200l; 64: 706-12.

7. Al-Amro SA, Al-Kharfi TM, Thabit AA, Al-Mofada SM. Risk factors for acute retinopathy of prematurity. Compr Ther 2007; 33: 737. [CrossRef]

8. Akkoyun I, Oto S, Yilmaz G, Gurakan B, Tarcan A, Anuk D, et al. Risk factors in the development of mild and severe retinopathy of prematurity. J AAPOS 2006; 10: 449-53. [CrossRef]

9. Chiang MF, Arons RR, Flynn JT, Starren JB. Incidence of retinopathy of prematurity from 1996 to 2000: analysis of a comprehensive New York state patient database. Ophthalmology 2004; III: 1317-25. [CrossRef]

10. Akçakaya AA, Yaylali SA, Erbil HH, Sadigov F, Aybar A, Aydin N, et al. Screening for retinopathy of prematurity in a tertiary hospital in Istanbul: incidence and risk factors. J Pediatr Ophthalmol Strabismus 2012; 49: 21-5. [CrossRef]

II. Ali AA, Gomaa NAS, Awadein AR, Al-Hayouti HH, Hegazy Al. Retrospective cohort study shows that the risks for retinopathy of prematurity included birth age and weight, medical conditions and treatment. Acta Paediatr 2017; 106: 1919-27. [CrossRef]

12. Martínez-Cruz CF, Salgado-Valladares M, Poblano A, Trinidad-Pérez MC. Risk factors associated with retinopathy of prematurity and visual alterations in infants with extremely low birth weight. Rev Invest Clin 2012; 64: 136-43.
13. Yau GS, Lee JW, Tam VT, Liu CC, Chu BC, Yuen CY. Incidence and risk factors for retinopathy of prematurity in extreme low birth weight Chinese infants. Int Ophthalmol 2015; 35: 365-73. [CrossRef]

14. Wu WC, Ong FS, Kuo JZ, Lai CC, Wang NC, Chen KJ, et al. Retinopathy of prematurity and maternal age. Retina 2010; 30: 327-31. [CrossRef]

15. Uchida A, Miwa M, Shinoda H, Koto T, Nagai N, Mochimaru H, et al. Association of Maternal Age to Development and Progression of Retinopathy of Prematurity in Infants of Gestational Age under 33 Weeks. J Ophthalmol 2014; 2014: 187929. [CrossRef]

16. Tunay ZÖ, Özdemir Ö, Acar DE, Öztuna D, Uraș N. Maternal Diabetes as an Independent Risk Factor for Retinopathy of Prematurity in Infants With Birth Weight of $1500 \mathrm{~g}$ or More. Am J Ophthalmol 20l6; 168: 201-6. [CrossRef]

17. Holmström G, Thomassen P, Broberger U. Maternal risk factors for retinopathy of prematurity--a population-based study. Acta Obstet Gynecol Scand 1996; 75: 628-35. [CrossRef]

18. Spiegler J, Jensen R, Segerer H, Ehlers S, Kühn T, Jenke A, et al. Influence of smoking and alcohol during pregnancy on outcome of VLBW infants. Z Geburtshilfe Neonatol 2013; 217: 215-9. [CrossRef]

19. Holmström G, Thomassen P, Broberger U. Maternal risk factors for retinopathy of prematurity--a population-based study. Acta Obstet Gynecol Scand 1996; 75: 628-35. [CrossRef]

20. Early Treatment for Retinopathy Of Prematurity Cooperative Group: Revised indications for the treatment of retinopathy of prematurity: results of the early treatment for retinopathy of prematurity randomized trial. Arch Ophthalmol 2003; I2I: 1684-94 [CrossRef]

21. Kanungo J, James A, McMillan D, Lodha A, Faucher D, Lee SK, et al Advanced maternal age and the outcomes of preterm neonates: a social paradox? Obstet Gynecol 20Il; II8: 872-7. [CrossRef]

22. Ko TJ, Tsai LY, Chu LC, Yeh SJ, Leung C, Chen CY, et al. Parental smoking during pregnancy and its association with low birth weight, small for gestational age, and preterm birth offspring: A birth cohort study. Pediatr Neonatol 20l4; 55: 20-7. [CrossRef]

23. Hirabayashi H, Honda S, Morioka I, Yokoyama N, Sugiyama D, Nishimura $\mathrm{K}$, et al. Inhibitory effects of maternal smoking on the development of severe retinopathy of prematurity. Eye (Lond) 2010; 24: 1024-7. [CrossRef]

24. Auger N, Abrahamowicz M, Wynant W, Lo E. Gestational age-dependent risk factors for preterm birth: associations with maternal education and age early in gestation. Eur J Obstet Gynecol Reprod Biol 2014; 176: 132-6. [CrossRef]

25. Ruiz M, Goldblatt P, Morrison J, Kukla L, Švancara J, Riitta-Järvelin $M$, et al. Mother's education and the risk of preterm and small for gestational age birth: a DRIVERS meta-analysis of I2 European cohorts. J Epidemiol Community Health 2015; 69: 826-33. [CrossRef]

26. Casas M, Cordier S, Martínez D, Barros H, Bonde JP, Burdorf A, et al. Maternal occupation during pregnancy, birth weight, and length of gestation: combined analysis of 13 European birth cohorts. Scand J Work Environ Health 2015; 41: 384-96. [CrossRef]

27. Wüst M. Maternal employment during pregnancy and birth outcomes: evidence from Danish siblings. Health Econ 2015; 24: 7II-25. [CrossRef]

28. Astolfi P, De Pasquale A, Zonta LA. Paternal age and preterm birth in Italy, 1990 to 1998. Epidemiology 2006; 17: 218-21. [CrossRef]

29. Alio AP, Salihu HM, McIntosh C, August EM, Weldeselasse H, Sanchez E, et al. The effect of paternal age on fetal birth outcomes. Am J Mens Health 2012; 6: 427-35. [CrossRef]

30. Shapiro GD, Bushnik T, Sheppard AJ, Kramer MS, Kaufman JS, Yang S. Paternal education and adverse birth outcomes in Canada. J Epidemiol Community Health 2017; 71: 67-72. [CrossRef] 